\title{
Microalgae for bioremediation of textile wastewater: An overview
}

\begin{abstract}
In early 1960's, the Japanese company Nihon Chlorella was the first one to make microalgae commercially available. Since then, the microalgae cultivation at industrial scale has grown and diversified significantly. Among the microalgae applications, bioremediation of textile wastewater is one the most promising technologies due to the simultaneous benefits: microalgae cultivation using textile wastewater as culture medium (bioremediation and $\mathrm{CO}_{2}$ mitigation) followed by microalgae lipid application (biodiesel production). Therefore, the aim of this work was to put a light on the main keys in bioremediation of textile wastewater using microalgae.
\end{abstract}

Keywords: microalgae, bioremediation, textile wastewater
Volume 6 Issue 5 - 2018

\author{
Cristiano José de Andrade, Lidiane Maria de \\ Andrade \\ Chemical Engineering Department of Polytechnic School, \\ University of São Paulo, Brazil
}

\begin{abstract}
Correspondence: Cristiano José de Andrade, Dempster MS Lab-Chemical Engineering Department of Polytechnic School of University of São Paulo, Lago Street, 250, bl B, $3^{\text {th }}$ floor, CEP 05508-080, São Paulo, SP, Brazil, Tel +55- I I-2648I558, Email eng.crista@gmail.com
\end{abstract}

Received: April 19, 2018 | Published: October II, 2018

\section{Introduction}

The textile industry generates large volumes of wastewater, as an example, $\approx 7 \times 10^{5}$ tons of organic dyes/year. Textile wastewater is a complex solution composed by organic dyes, phosphates, nitrates and heavy metals. Thus, textile wastewater has a potential environmental hazard and should be properly treated. When compared to physicchemical methods that can be applied for textile wastewater treatment (photochemical, activated carbon), biological systems have advantages mainly in terms of cost effectiveness, eco-friendly approach, easy and safe operation-green chemistry concept. Biological methods include the application of bacteria, yeasts, fungi and microalgae (or their metabolites) in situ or ex situ. In this sense, microalgae have risen prominence, mostly due to their potential to simultaneously bioremediation, $\mathrm{CO}_{2}$ mitigation and also high added-value molecules production..$^{1-3}$ In addition, there are approximately 50,000 species of microalgae present on earth, which represents countless strategies of microalgae study and application. ${ }^{1}$

\section{Microalgae cultivation systems}

There are many microalgae cultivation systems, in which it can be classified into 3 groups (I) suspended culture systems, (II) microalgae immobilization and (III) innovative submersible aquatic microalgae cultivation technology. 4,5

\section{Suspended culture systems (open, close and hybrid systems)}

Open: The raceway pond-an open system for microalgae cultivationis the most used cultivation system at industrial scale, due to easy scale up and low cost (facilities). On the other hand, as an open system, water loss by evaporation should ne take into account. Contamination is other significant issue.

Close: Compared with open ponds, closed bioreactors significantly reduce water loss and contamination. Closed bioreactors include flat plate bioreactors, tubular photobioreactors and bag systems. However, the high cost restricts the use of closed bioreactor at large-scales.

Hybrid: It is a two-stage cultivation system, in which in the first stage closed photobioreactors are used to microalgae cultivation (inoculum for the second stage). Then, microalgae are cultivated in open ponds (volume first stage $<<<<$ volume second stage). The hybrid cultivation system minimizes the contamination in the second stage and also favors a specific dominance of the chosen microalgae. However, the first stage (high cost) limits the hybrid applications at large-scales.

\section{Microalgae immobilization}

One of the major bottlenecks for microalgae suspended culture systems is the clarification (biomass separation from culture medium), that includes chemical, mechanical, electrical and biological approaches. Thus, microalgae immobilization is an interesting strategy. When compared to microalgae suspended culture system, microalgae immobilization shows higher productivity in bioremediation applications, no or lower washout phenomenon and mainly easier downstream processing (harvesting and water recycling). However, the high cost is the limiting factor for microalgae immobilization.

\section{Innovative submersible aquatic microalgae cultivation technology}

As mentioned both suspended microalgae culture system and microalgae immobilization have drawbacks. Thus, alternative systems have been drawn attention, for instance Bussel ${ }^{6}$ that describes a patented floating pond system in which microalgae are grown in a controlled space separated from surrounding water.

\section{Bioremediation of textile wastewater using microalgae}

As already mentioned microalgae can be applied in different types of wastewater such as textile, metropolitan wastewater, swine manure, dairy, poultry, winery, tannery, paper mill and olive mill., ${ }^{4,7}$

Particularly regarding textile wastewater, is been estimated that more than 100,000 different dyes has been globally used by industries. The dye industry generates $7 \times 10^{5}$ tons of organic dyes/year, in which $40 \%\left(\approx 2.8 \times 10^{5}\right.$ tons/year $)$ are incorrectly disposal. ${ }^{1,2}$ Textile wastewater contains organic dyes, phosphates, nitrates, trace heavy metals ( $\mathrm{Pb}, \mathrm{Cd}, \mathrm{Zn}, \mathrm{Mn}, \mathrm{Cr}, \mathrm{Ni}, \mathrm{Cu}, \mathrm{Fe}, \mathrm{Ar}$ ), etc. (Table 1), that have 
potential environmental hazard. In addition, textile wastewater has aesthetic pollution (color) even at low concentration. In this sense, the UNESCO's World Water Development Report ${ }^{8}$ raised concern about the hazardous industrial wastes, in particular dye effluents. ${ }^{2}$ Several physic-chemical methods can be applied for textile wastewater treatment such as fenton's reagent, ozonation, photochemical, $\mathrm{NaOCl}$, cucurbituril, electrochemical destruction, activated carbon, peat, wood chips, silica gel, membrane filtration, ion exchange and irradiation, however these methods are not aligned to the green-chemistry concept and have many drawbacks (e.g. expensive, low efficiency). In this sense, biological approaches are the most prominent eco-friendly treatment, in which microalgae (Chlorella vulgaris, Chlorella pyrenoidosa, Spirogyra sp., Oscillatoria tenuisin and Scenedesmus sp.) have risen prominence due to their potential to simultaneously textile wastewater bioremediation, $\mathrm{CO}_{2}$ mitigation and produce high added-value molecules as long-chain polyunsaturated fatty acids; phenolic compounds; volatile compounds; sterols; proteins, amino acids, peptides; vitamins; polysaccharides and pigments. . $^{1,2,9,10}$

Even with a great potential for bioremediation of texture wastewater, the microalgae cultivation still faces many obstacles, for instance the complex chemical composition of texture wastewater affects the microalgae growing (reproducibility), contamination (bacteria) and design of the microalgae cultivation system. Therefore, further research is needed.

Table I Textile wastewater: chemical properties'

\begin{tabular}{llll}
\hline Parameter & Value & Parameter & Value \\
\hline $\mathrm{pH}$ & $5.6-9.0$ & $\mathrm{~Pb}$ & $0.5 \mathrm{mg} / \mathrm{L}$ \\
Temperature & $35-45^{\circ} \mathrm{C}$ & $\mathrm{Cd}$ & $0.3 \mathrm{mg} / \mathrm{L}$ \\
Conductance & $6.89 \mathrm{mS}$ & $\mathrm{Zn}$ & $1 \mathrm{mg} / \mathrm{L}$ \\
$\mathrm{COD}$ & $250-8,000 \mathrm{mg} \mathrm{O}_{2} / \mathrm{L}$ & $\mathrm{Mn}$ & $2 \mathrm{mg} / \mathrm{L}$ \\
$\mathrm{BOD}$ & $50-550 \mathrm{mg} \mathrm{O} / \mathrm{L}$ & $\mathrm{Cr}$ & $1.5 \mathrm{mg} / \mathrm{L}$ \\
$\mathrm{TSS}$ & $100-700 \mathrm{mg} / \mathrm{L}$ & $\mathrm{Ni}$ & $1 \mathrm{mg} / \mathrm{L}$ \\
$\mathrm{TDS}^{+1}$ & $5,000-10,000 \mathrm{mg} / \mathrm{L}$ & $\mathrm{Cu}$ & $0.2 \mathrm{mg} / \mathrm{L}$ \\
$\mathrm{NH}_{4}^{+1}$ & $50 \mathrm{mg} / \mathrm{L}$ & $\mathrm{Fe}$ & $0.2 \mathrm{mg} / \mathrm{L}$ \\
$\mathrm{NO}_{2}^{-1}$ & $350 \mathrm{mg} / \mathrm{L}$ & $\mathrm{Ar}$ & $0.01 \mathrm{mg} / \mathrm{L}$ \\
$\mathrm{Total}^{-1} \mathrm{PO}_{4}^{-1}$ & $4.0-12 \mathrm{mg} / \mathrm{L}$ & Total CN & $1 \mathrm{mg} / \mathrm{L}$ \\
$\mathrm{SO}_{4}^{-2}$ & $50-900 \mathrm{mg} / \mathrm{L}$ & Free residual Cl & $100-500 \mathrm{mg} / \mathrm{L}$ \\
\hline
\end{tabular}

\section{Conclusion}

The textile industry generates large volumes of wastewater $\approx 7 \times 10^{5}$ tons of organic dyes/year. Textile wastewater is composed by organic dyes, phosphates, nitrates, heavy metals, among others that represent environmental hazard. When compared to physic-chemical methods (ozonation, electrochemical destruction, activated carbon), biological methods (bioremediation using microalgae) show advantages in terms of cost effectiveness, easy scale up and mainly the potential to simultaneously carried out the bioremediation, $\mathrm{CO}_{2}$ mitigation and biosynthesize high-added value molecules. In addition, there is no consensus on the best microalgae cultivation system.

\section{Acknowledgements}

The authors are grateful to Dempster Mass Spectrometry Lab, Polytechnic School of University of São Paulo.

\section{Conflict of interest}

The authors declare no conflict of interest.

\section{References}

1. Fazal T, Mushtaq A, Rehman F, et al. Bioremediation of textile wastewater and successive biodiesel production using microalgae. Renewable and Sustainable Energy Reviews. 2018;82:3107-3126.

2. Garcia Segura S, Ocon JD, Chong MN. Electrochemical oxidation remediation of real wastewater effluents-A review. Process Safety and Environmental Protection. 2018;113:48-67.

3. Vikrant K, Giri BS, Raza N, et al. Recent advancements in bioremediation of dye: Current status and challenges. Bioresource Technology. 2018;253:355-367.

4. Cai T, Park SY, Li Y. Nutrient recovery from wastewater streams by microalgae: Status and prospects. Renewable and Sustainable Energy Reviews. 2013;19:360-369.

5. Maity JP, Bundschuh J, Chen CY, et al. Microalgae for third generation biofuel production, mitigation of greenhouse gas emissions and wastewater treatment: present and future perspectives-A mini review. Energy. 2014;78:104-113.

6. Bussell S. Submersible aquatic algae cultivation system. 2008.

7. Zhou W, Cheng Y, Li Y, et al. Novel fungal pelletization-assisted technology for algae harvesting and wastewater treatment. Applied Biochemistry and Biotechnology. 2012;167(2):214-228.

8. UNESCO. The United Nations World Water Development. 2012. 154 p.

9. Robinson T, Mcmullan G, Marchant R, et al. Remediation of dyes in textile effluent: a critical review on current treatment technologies with a proposed alternative. Bioresource Technology. 2001;77(3):247-255.

10. Andrade LM, Andrade CJ, Dias M, et al. Chlorella and Spirulina microalgae as sources of functional foods, nutraceuticals, and food supplements; an overview. MOJ Food Processing \& Technology. 2018;6(2):1-14. 